\section{Hemospray rescue treatment of gastroenteric anastomotic bleeding}

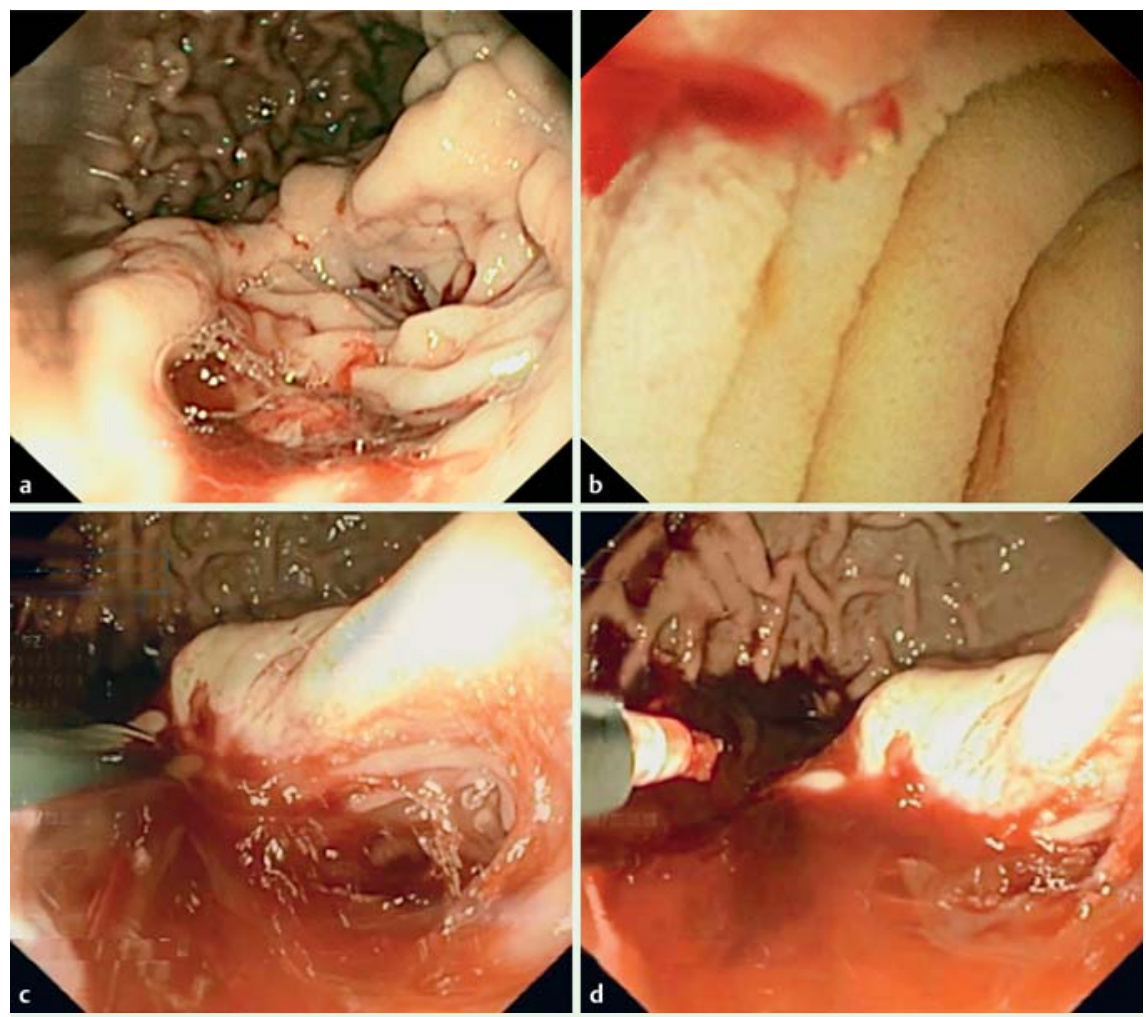

Fig. 1 Endoscopic images from a 52-year-old man who had undergone a gastroenteric anastomosis for a duodenal bulb stenosis showing: a an oozing bleeding point in the border of the anastomosis; b the bleeding point in close-up underwater view; $\mathbf{c}$ attempted treatment of the bleed with injection of a solution of saline and epinephrine, without success; $\mathbf{d}$ the bleeding site obscured by blood and clots.
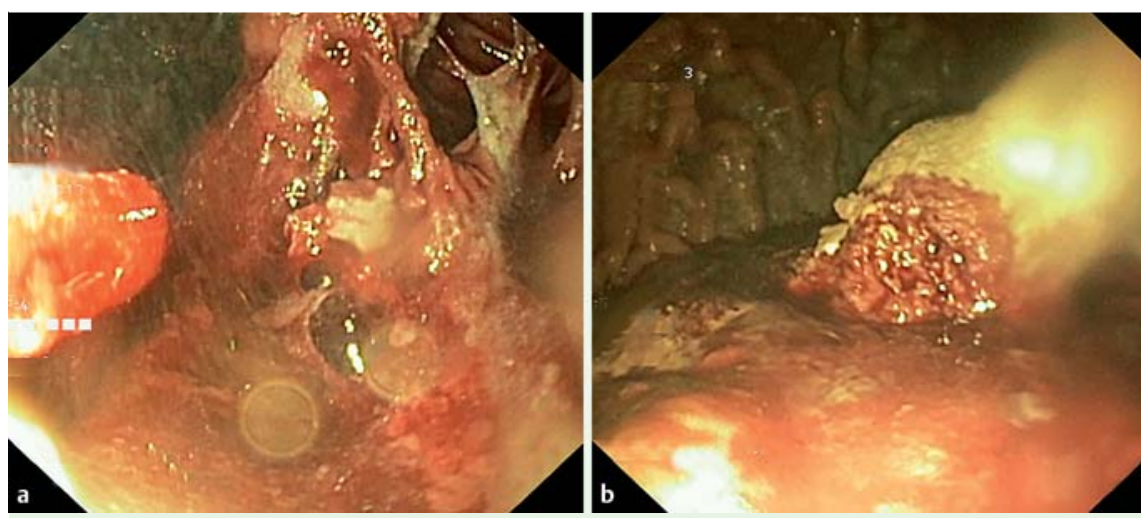

Fig. 2 Endoscopic views showing the effect of using the powder with hemostasis being successfully achieved.

A 52-year-old man with chronic pancreatitis and pancreatic exocrine insufficiency developed a duodenal bulb stenosis that caused postprandial vomiting. He underwent a gastroenteric anastomosis to restore the intestinal flow. He was readmitted 30 days after discharge with hematemesis, hypovolemic shock, and severe anemia (hemoglobin $6.6 \mathrm{~g} / \mathrm{dL}$ ). He was re-
GmbH, Marburg, Germany) to create a large cushion to jam the vessel, but bleeding restarted at an increased rate $(\bullet$ Video 1). We attempted to inject a solution of saline and epinephrine, without success ( Fig.1 c). The increased blood flow and clots obscured the bleeding site, rendering it difficult to perform any further conventional treatment that required accurate localization of the bleeding source ( $\bullet$ Fig. $1 \mathrm{~d}$ ).

We decided to use Hemospray (Cook Medical, Winston Salem, North Carolina, USA). A 10-Fr catheter was advanced approximately $2 \mathrm{~cm}$ out of the scope and was placed approximately $2 \mathrm{~cm}$ from the bleeding site. Multiple consecutive bursts created a hemostatic powder barrier, which successfully stopped the bleed ( $\bullet$ Fig. 2; $\bullet$ Video 1). There were no adverse events and no late recurrent bleeding.

Current hemostatic techniques include injection therapy (epinephrine, sclerosants, or fibrin glue), thermal therapy (heater probe, bipolar cautery, or argon plasma coagulation), and mechanical therapy (standard metal clips, over-the-scope clips, or band ligation). However, these techniques do have some limitations, especially in the case of massive bleeding that obscures the endoscopic view. One possible major advantage of the hemostatic powder over the current endoscopic modalities may be its ability to control bleeding from obscured bleeding sites. The advent of Hemospray potentially obviates the need for en face therapeutic positioning.

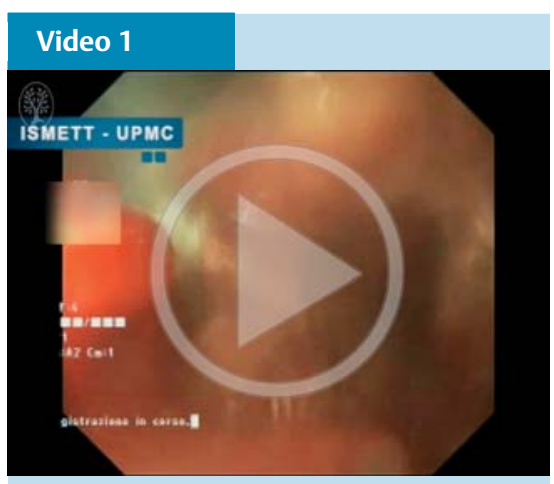

Endoscopic view of the bleeding site being treated with fibrin glue then epinephrine, which led to increased bleeding, and finally with multiple bursts of hemostatic powder, which successfully stopped the bleeding.

Endoscopy_UCTN_Code_TTT_1AO_2AD

Competing interests: None 
Antonino Granata, Dario Ligresti, Gabriele Curcio, Luca Barresi, Ilaria Tarantino, Rosalba Orlando, Mario Traina

Endoscopy Service, Department of Diagnostic and Therapeutic Services, IRCCS - ISMETT (Istituto Mediterraneo per i Trapianti e Terapie ad alta specializzazione), Palermo, Italy
Bibliography

DOI http://dx.doi.org/

10.1055/s-0034-1392322

Endoscopy 2015; 47: E327-E328

(c) Georg Thieme Verlag KG

Stuttgart · New York

ISSN 0013-726X
Corresponding author Antonino Granata, MD ISMETT/UPMC

Via Tricomi 5

90127 Palermo

Italy

Fax: +39-091-2192400

(specify Endoscopy Service) agranata@ismett.edu 